\title{
Retinocoroidite toxoplásmica reativada provavelmente por cirurgia refrativa - Laser In Situ Keratomileusis - LASIK
}

\author{
Probable reactivation of toxoplasmic retinochoroiditis by \\ refractive surgery - Laser In Situ Keratomileusis - LASIK
}

Afonso Medeiros ${ }^{1}$, Marília Medeiros² ${ }^{2}$ Elisabeto Ribeiro Gonçalves³ ${ }^{3}$ Isadora Meyer ${ }^{4}$, João Pessoa de Souza Filho ${ }^{5}$

\section{Resumo}

O presente trabalho objetiva demonstrar provável relaço entre recorrência de toxoplasmose ocular e cirurgia refrativa (LASIK). Trata-se de relato de caso de um paciente de 33 anos de idade com recorrência de retinocoroidite toxoplásmica após cirurgia de LASIK. O exame fundoscópico do olho esquerdo revelou foco de retinocoroidite em atividade, satélite a cicatriz antiga de toxoplasmose ocular, 17 dias após cirurgia de LASIK. Os autores apresentam subsídios para o estabelecimento de relação causal entre LASIK e a reativação de retinocoroidite toxoplasmática.

Descritores: Ceratomileuse assistida por excimer laser in situ/efeitos adversos; Toxoplasmose ocular/etiologia; Coriorretinite; Miopia/cirurgia; Recidiva; Relatos de casos.

\footnotetext{
${ }^{1}$ Chefe do Departamento de Uveíte do Instituto de Olhos do Recife - Recife (PE), Brasil; ${ }^{2}$ Oftalmologista do Departamento de Cirurgia Refrativa do Instituto de Olhos do Recife - Recife (PE), Brasil;

${ }^{3}$ Chefe do Serviço de Retina e Vítreo e de Eletrofisiologia Ocular do Instituto de Belo Horizonte - Belo Horizonte (MG), Brasil; ${ }^{4}$ Médica Residente em Oftalmologia do Instituto de Olhos do Recife - Recife (PE), Brasil;

${ }^{5}$ Professor Adjunto de Oftalmologia da Universidade Federal da Paraíba - UFPA - João Pessoa (PB), Brasil e da Universidade Federal de Campina Grande - UFCG - Campina Grande (PB), Brasil.

Instituição: Instituto de Olhos do Recife (Recife-PE)
}

Recebido para publicação em: 28/1/2010 - Aceito para publicação em 19/3/2010 


\section{INTRODUÇÃO}

A manifestação ocular mais comum da toxoplasmose consiste em focos de necrose retiniana, com subjacentes coroidite e vitreíte. A lesão se mantém ativa durante semanas e, depois de cicatrizada, pode conter cistos do Toxoplasma gondii, de forma que o protozoário permanece viável nos tecidos durante anos. A relação entre rotura traumática da parede dos cistos toxoplásmicos e recorrência da toxoplasmose ocular pode ser explicada pela reação de hipersensibilidade desencadeada pela liberação de antígenos intracísticos. Essa liberação alteraria o delicado equilíbrio de imunorregulação, dando início ao processo de sensibilização retiniana. Já foi demonstrado em animais de laboratórios modificações na imunorregulação medidas também pelo estresse e, por isso, acredita-se que o estresse emocional pode atuar como fator causal ou de recorrência de algumas formas de uveíte ${ }^{(1)}$. Alterações no mecanismo de imunorregulação podem ser atribuídas a causas relacionadas ao hospedeiro (alterações na imunidade celular, por exemplo), ao parasita (crescimento dos cistos ou reação cruzada de antígenos, induzindo autoimunidade) ou externos, como infecções bacterianas ou virais, debilitação física e emocional, exposição a radiações ionizantes (UV). Esses fatores de estresse podem atuar, igualmente, como gatilho para a recorrência da uveíte ${ }^{(2)}$.

Apresentamos um caso de recidiva da toxoplasmose ocular, possivelmente, desencadeada por cirurgia refrativa (LASIK).
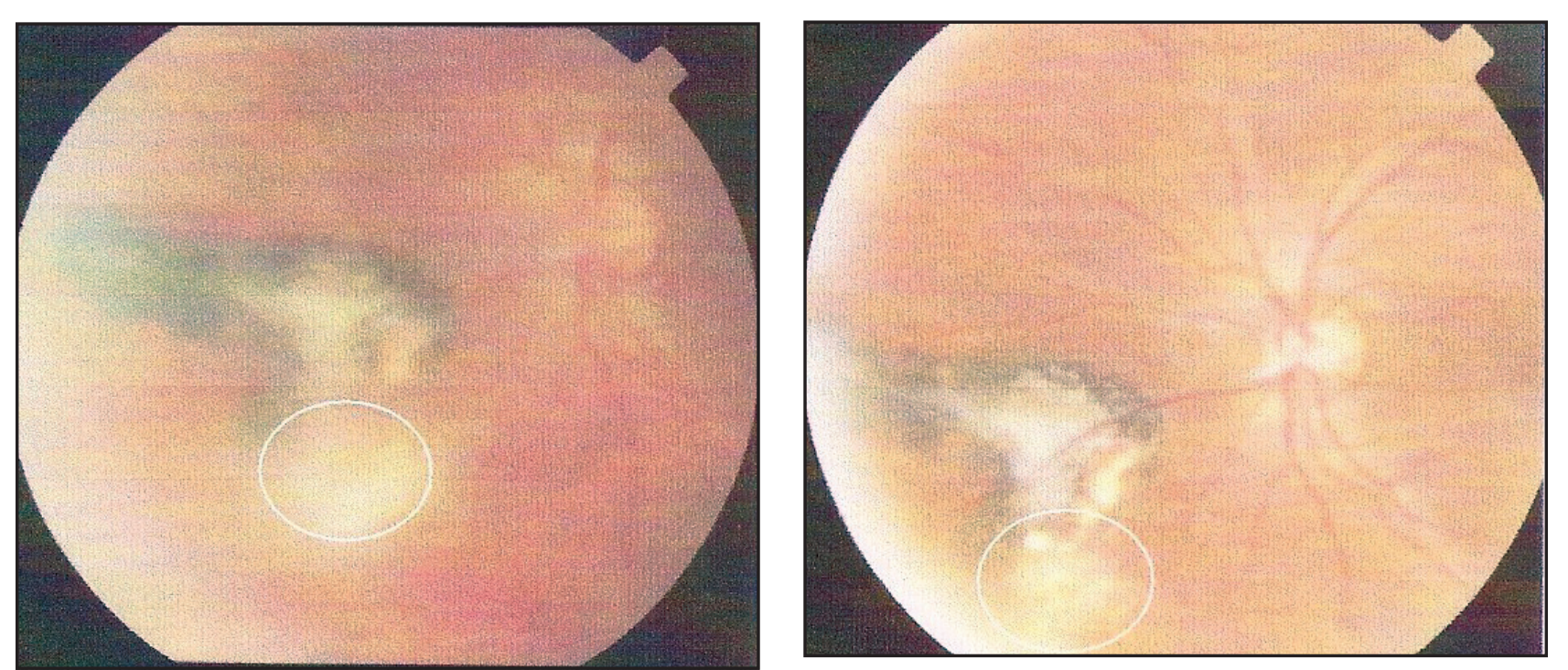

Figura 1: A - Retinografia do OE, 17 dias pós-LASIK. Vítreo reativo, turvo, com foco em atividade, satélite à cicatriz antiga de retinocoroidite toxoplásmica; B - Retinografia do OE, 49 dias pós-LASIK; Vítreo claro, remissão do foco inflamatório

\section{Relato do Caso}

Paciente do sexo masculino, 33 anos, leucodérmico, com passado de retinocoroidite por toxoplasmose OE há 6 anos, tratado, na ocasião, com sulfadiazina e pirimetamida. À oftalmoscopia do OE, apresentava cicatriz de retinocoroidite pigmentada medindo 4DP, de localização nasal à papila. Foi submetido à cirurgia refrativa (Laser Assisted in Situ Keratomileusis - LASIK) em ambos os olhos (AO), inicialmente em OD, com intervalo de 4 dias para o outro olho, com excimer laser Nidek, modelo EC5000. Foi prescrito colírio de tobramicina associado à dexametasona no pós-operatório de $\mathrm{AO}$. No $1^{\circ}$ DPO de AO evoluiu sem intercorrências, com acuidade visual sem correção (AV-SC) de 20/25 AO. No $13^{\circ}$ DPO do OE, queixou-se de turvação neste olho, com redução da AV-SC para 20/60 em OE. À biomicroscopia do OE, apresentava precipitados ceráticos finos $(+)$, células aquosas $(+)$, inversão do sistema de plicatas, células vítreas $(+)$, presença do anel de Weiss. A pressão intraocular era de $15 \mathrm{mmHg}$ e na fundoscopia notava-se foco ativo de retinocoroidite, satélite (inferior) à antiga cicatriz nasal (figura 1A).

A sorologia para toxoplasmose revelou anticorpo anti IgG (IMF indireta) reagente 1/16.000.

Submetido ao tratamento clássico com sulfadiazina, pirimetamida, prednisona e ácido folínico, houve boa resposta, com remissão do foco inflamatório retinocoroidiano (figura 1B) e melhora da AV.

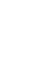




\section{Discussão}

A técnica de LASIK, respeitados os limites de indicação, é considerada procedimento refrativo seguro e as complicações associadas a ela são pouco frequentes, estando diretamente relacionadas à experiência do cirurgião e à qualidade dos equipamentos utilizados ${ }^{(3)}$. $\mathrm{O}$ LASIK se mostra seguro também para o seguimento posterior, pois as alterações retinianas, encontradas após seu uso parecem refletir a predisposição natural dos olhos míopes a patologias degenerativas da retina ${ }^{(4)}$. A medida do comprimento axial não parece apresentar diferença significativa antes e durante a cirurgia de LASIK, mas ocorre diminuição da espessura do cristalino durante o período de sucção. É sugerido que, em pacientes jovens, nos quais o vítreo anterior encontra-se aderido à cápsula posterior, essa diminuição da espessura do cristalino, sem que haja alteração no comprimento axial, gere grande tração anterior sobre o corpo vítreo. Isso poderia tracionar áreas de forte aderência vítrea, como a mácula, causando buraco macular, e, nas áreas de pouca aderência vitreorretiniana, causar descolamento do vítreo $^{(5)}$.

O que nós discutimos é a possibilidade de relação causal entre o LASIK e a recorrência da toxoplasmose retiniana. Na literatura científica há, em 2005, relato de um caso de reativação de toxoplasmose ocular em um homem de 34 anos, 52 dias após submeter-se à cirurgia de LASIK $^{(2)}$. Caso semelhante ocorreu 5 dias após realização do mesmo procedimento, em um homem de 24 $\operatorname{anos}^{\left({ }^{(}\right)}$. Nesses dois pacientes, durante exame pré-operatório, não foi vista qualquer alteração ocular, além da ametropia a ser corrigida e de cicatriz pigmentada de coriorretinite no mesmo olho, acometido após a cirurgia. Em ambos os casos, os pacientes foram tratados com esteróides tópicos no pós-operatório imediato, associados a colírio de tobramicina e, em um deles, foi usado também carboximetilcelulose tópico até a introdução do tratamento da coriorretinite ${ }^{(5,6)}$.

As referências são mais numerosas quanto à cirurgia da catarata como fator causal dessa reativação, que atuaria de maneira similar ao provável mecanismo introduzido pelo LASIK. O exato mecanismo etiopatogênico não é conhecido, embora o trauma mecânico induzido pela cirurgia esteja entre as possíveis causas. Argumenta-se que a rotura de cistos toxoplasmáticos, até então inativos, podem ser responsabilizada pela reativação da toxoplasmose pósfacectomia. Embora nunca tenha sido provado em estudos com animais, sugere-se também que a parede do
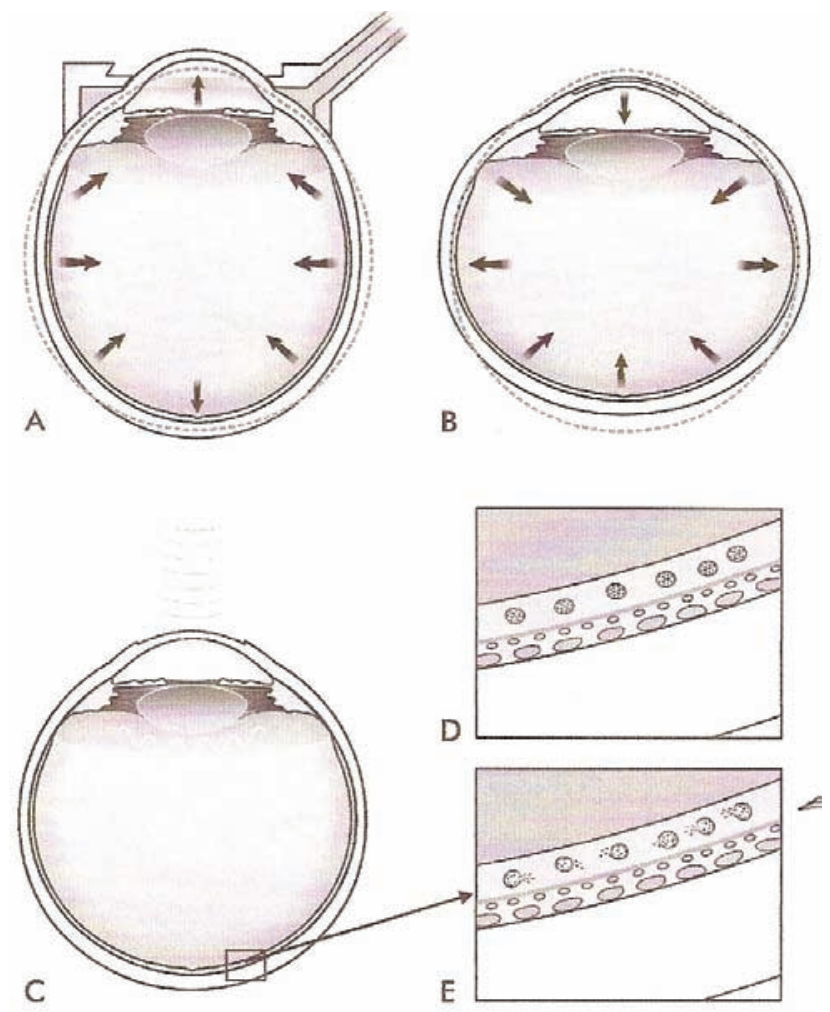

Figura 2: Atuação da compressão/descompressão ântero-posterior e da onda de choque induzida pelo laser na gênese das roturas retinianas, das alterações maculares e da fratura dos cistos toxoplásmicos intrarretinianos. A - Aumento do comprimento axial do olho causado pelo anel de sucção; Simultaneamente, como o globo é um sistema fechado, ele se contrai ao longo do eixo horizontal, reduzindo o diâmetro equatorial. A lente e a hialóide anterior, solidárias, são deslocadas para frente, o que pode acelerar o deslocamento ou gerar trações na base do vítreo; B - Quando a sucção é repentinamente relaxada, a excessiva descompressão causa expansão equatorial associada ao encurtamento axial do globo. Esses eventos podem causar uma tração vitreorretiniana aguda na base vítrea e no polo posterior; $\mathrm{C}$ - Adicionalmente, a energia da onda de choque induzida pelo laser sobre a córnea durante a fotoablação, dirigiu-se para trás, podendo desempenhar importante papel no surgimento do descolamento posterior do vítreo; D e E - Representação esquemática dos cistos toxoplásmicos intrarretinianos íntegros (D) e rotos (E)

cisto toxoplásmico perde sua elasticidade com o envelhecimento e pode sofrer fratura como resultado de trauma contuso ${ }^{(7)}$. Além da própria cirurgia, provavelmente outros fatores relacionados a ela (energia transmitida ao olho durante a facoemulsificação, estresse psicológico da cirurgia ou uso pós-operatório de esteróides tópicos) podem contribuir para o desenvolvimento de recorrências. Alguns desses fatores são compartilhados com a cirurgia de LASIK.

É proposto que pelo menos um dos prováveis mecanismos seja semelhante na facectomia e no LASIK: as ondas de choques acústicas geradas dentro do globo durante as cirurgias ${ }^{(2,6)}$. O excimer laser provoca uma onda 
de choque de $3.3 \mathrm{~km} / \mathrm{seg}$ em 40 nanossegundos e gera uma pressão acima de 100 atmosferas. Admiti-se, embora com incertezas relacionadas às bases fisiopatológicas, que a força da amplitude da onda fotoacústica gerada durante a fotoablação da córnea com o excimer laser pode ser considerada perigosa para a retina e estruturas subretinianas ${ }^{(8,9)}$. Outras fontes afirmam o contrário: essas ondas, ao chegarem à retina, já teriam sido significantemente atenuadas, sem causar mais danos ${ }^{(10)}$. A hipertensão e a rápida descompressão é outro possível fator envolvido nas complicações retinianas do LASIK $^{(2,6)}$. Postula-se que a súbita hipertensão durante a sucção realizada pelo ceratótomo e a imediata redução da pressão com o relaxamento dessa sucção, pode exercer uma tração mecânica (estiramento) da base vítrea, levando a alterações retinianas e, entre elas, o buraco macular e o descolamento de retina ${ }^{(8)}$. Talvez, o mecanismo de compressão/descompressão tenha atuado decisivamente na recorrência da toxoplasmose retiniana que se seguiu ao LASIK no caso relatado, embora seja mais lógico esperar que esses dois mecanismos (ondas de choque e compressão/descompressão) se consorciem para produzir as alterações do complexo vitreorretiniano. A facectomia intracapsular ou extracapsular convencionais e a facoemulsificação atuariam através do trauma contuso e das ondas ultrassônicas, liberando radicais livres que atuariam como mediadores inflamatórios e provocando fraturas nos cistos toxoplásmicos quiescentes. No LASIK temos a presença da onda de choque fotoacústica e o mecanismo de compressão/ descompressão, possivelmente provocando alterações vitreorretinianas já descritas. É possível que a onda de choque atue diretamente sobre o cisto, rompendo sua parede e liberando antígeno toxoplásmicos, à semelhança do que faz a onda sônica da facoemulsificação ${ }^{(2)}$. As alterações induzidas pela compressão/descompressão também poderiam atuar sobre os cistos, imprimindo-lhes forças que deformariam suas paredes, culminando com fratura e liberação do material intracístico potencialmente antigênico. A fisiopatogenia poderia também consorciar os dois mecanismos: ondas de choque e compressão/ descompressão (figura 2).

A recorrência da toxoplasmose poderia ser apenas uma coincidência e a pequenez de casos descritos não se presta ao estabelecimento de uma relação causal segura e definitiva entre a cirurgia do LASIK e essa refração. Por outro lado, não podemos descartar a associação, conhecendo os princípios da cirurgia do LASIK e seus possíveis efeitos adversos sobre o complexo vitreorretiniano.

\section{Abstract}

The aim of this article is to demonstrate the probable relationship between the recurrence of toxoplasmic retinochoroiditis and refractive surgery (LASIK). The case consists in a toxoplasmic retinochoroditis recurrence observed in a 33-year-old patient after a LASIK surgery. Fundoscopy revealed a retinochoroiditis focus in activity in the left eye seventeen days after the surgery, adjacent to an old scar of ocular toxoplasmosis. The authors present findings that reinforce possible causal links between LASIK and the recurrence of toxoplasmic retinochoroiditis.

Keywords: Keratomileusis, laser in situ/adverse effects ; Ocular toxoplasmosis/etiology; Chorioretinitis; Myopia/surgery; Recurrence; Case reports.

\section{RefERÊNCIAS}

1. Tabbara KF. Ocular toxoplasmosis. Int Ophthalmol. 1990;14(56): 349-51.

2. Barbara A, Shehadeh-Masha'our R, Sartani G, Garzozi HJ. Reactivation of ocular toxoplasmosis after LASIK. J Refract Surg. 2005;21(6): 759-61.

3. Pereira T, Forseto AS, Nosé W. Complicações pré e pósoperatórias em 1.000 olhos submetidos a LASIK. Arq Bras Oftalmol. 2001;64(6): 499-506.

4. Nassaralla JJ, Santos RR, Nassaralla BA. Alterações retinianas após LASIK. Rev Bras Oftalmol. 2002;61(12): 845-52.

5. Mirshahi A, Kohnen T. Effect of microkeratome suction during LASIK on ocular structures. Ophthalmology. 2005;112(4):645-9.

6. Fontaine F., Fourmaux E., Colin J. Reactivation of ocular toxoplasmosis after laser in situ keratomileusis. J Fr Ophtalmol. 2006;29(5): 11.

7. O'Connor GR. 15th Edward Jakson Memorial Lecture. Factors related to the initiation and recurrence of uveitis. Am J Ophthalmol. 1983;96(3): 577-99.

8. Melki AS, Azar DT. Lasik complications: etiology, management, and prevetion. Surv Ophthalmol. 2001;46(2): 95-116.

9. Loewenstein A, Goldstein M, Lazar M. Retinal pathology occurring after excimer laser surgery or phakic intraocular lens implantation: evaluation of possible relationship. Surv Ophthalmol. 2002;47(2): 125-35.

10. Spörl E, Gruchmann T, Genth U, Mierdel P, Seiler T. Laserinduced pressure waves in the eye. Propagation characteristics. Ophthalmologe. 1997;94(8): 578-82.

\footnotetext{
Endereço para correspondência:

Isadora Meyer

Rua Vicente, $n^{\circ} 137$

CEP 52020-130 - Recife (PE), Brasil

Tel: (81) 32679204 / (81) 86527812

Fax: (81) 3423-5353.

E-mail: isadorameyer@yahoo.com.br.
} 